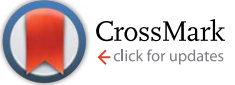

Cite this: RSC Adv., 2017, 7, 8589

\title{
Insight into a high temperature selective oxidation of HP40 alloy under a $\mathrm{H}_{2}-\mathrm{H}_{2} \mathrm{O}$ environment $\dagger$
}

\author{
Binbin Bao, Jinglei Liu, * Hong Xu, Bo Liu, Kai Zhang and Zhaorong Jin \\ In the present work, a selective oxidation process of $\mathrm{HP} 40$ alloy at $1050{ }^{\circ} \mathrm{C}$ under a $\mathrm{H}_{2}-\mathrm{H}_{2} \mathrm{O}$ environment \\ were studied in detail by means of SEM, EDS, GD-OES, XRD, Raman spectra and XPS. The results revealed \\ that selective oxidation of $\mathrm{Mn}$ and $\mathrm{Cr}$ elements was realized, and the oxide scale preferentially grew via grain \\ boundary rather than via grain lattice. The oxide scales were composed of a majority of $\mathrm{MnCr}_{2} \mathrm{O}_{4}$ spinel and \\ a spot of $\mathrm{Cr}_{2} \mathrm{O}_{3}$ throughout the oxidation process. Mn existed in the form of $\mathrm{Mn}^{2+}$ ions on the surface, while \\ $\mathrm{Cr}$ existed in various species. Metal hydroxides appeared on the surface approved by spectra of the $\mathrm{O}$ is \\ region, and the relative amount of them decreased with oxidation time.
}

Received 27th October 2016 Accepted 23rd January 2017

DOI: 10.1039/c6ra25933b

rsc.li/rsc-advances

inhibited. And the low oxygen partial pressure environment can

\section{Introduction}

Ethylene is the building block of chemical industry, and it is mainly produced by thermal cracking of hydrocarbons. The thermal cracking process is usually conducted at higher temperatures in cracking coils constructed of $\mathrm{Fe}-\mathrm{Cr}-\mathrm{Ni}$ alloy (e.g. HP40, HK40). ${ }^{1-4}$ The inner surface of coils is gradually covered by coke, and the thickness of the coke layer increases with the cracking time. The coke layer deposited on the inner surface will greatly increase the pressure drop in coils and reduce heat transfer from coils to cracking gas. ${ }^{3,4}$ Moreover, coke adhered on the surface will react with coil alloy and further lead to serious carburization. In practice, the cracking coils have to be shut down to remove coke when the maximum skin temperature of coils is reached. Carburizing, and decoking operation will significantly shorten the lifetime of coils and reduce ethylene yield. Therefore, inhibiting coking is meaningful work in terms of achieving high yield of ethylene and long-term running of cracking coils.

Many studies have demonstrated that catalytic coking, caused by the catalysis of Fe and Ni elements or their oxides, is one of the main mechanisms for coke formation. ${ }^{1-5}$ And catalytic coking is also responsible for serious carburization on the surface layer of coils. Fabrication of inert coatings or layers on the coils to protect $\mathrm{Fe}$ and Ni elements from cracking gas is an effective method to inhibit coking and carburizing. ${ }^{4,6-8}$ It has been recently reported that selective oxidation of Mn and Cr elements on the surface can be realized at high temperature under low oxygen partial pressure, since the oxygen affinities of $\mathrm{Cr}$ and $\mathrm{Mn}$ are higher than that of $\mathrm{Fe}$ and $\mathrm{Ni}^{3,9,10} \mathrm{Fe}$ and $\mathrm{Ni}$ elements are absent in the formed oxide scale, thereby catalytic coking and carburizing can be significantly

State-Key Laboratory of Chemical Engineering, School of Mechanical and Power Engineering, East China University of Science and Technology, Shanghai, 200237, China.E-mail: ljlei@ecust.edu.cn; Fax: +86021 64253810; Tel: +8602164251315

$\dagger$ Electronic supplementary information (ESI) available. See DOI: 10.1039/c6ra25933b be easily obtained by a gas mixture of $\mathrm{H}_{2}-\mathrm{H}_{2} \mathrm{O} .^{3,10}$ Together with facile fabrication and low cost, pre-oxidation of cracking coils under $\mathrm{H}_{2}-\mathrm{H}_{2} \mathrm{O}$ environment becomes a promising technique to inhibit catalytic coking as well as carburizing.

Researchers $^{3,9}$ have oxidized $\mathrm{Fe}-\mathrm{Cr}-\mathrm{Ni}$ alloys at different temperature under $\mathrm{H}_{2}-\mathrm{H}_{2} \mathrm{O}$ environment and studied the composition of oxide scales and their effect on coke formation. The results revealed that the formed oxide scales mainly composed of $\mathrm{MnCr}_{2} \mathrm{O}_{4}$ spinel and $\mathrm{Cr}_{2} \mathrm{O}_{3}$, and could effectively inhibit catalytic coke formation. According to some reports, the stabilities of $\mathrm{MnCr}_{2} \mathrm{O}_{4}$ spinel and $\mathrm{Cr}_{2} \mathrm{O}_{3}$ are different in both high temperature oxidative environment and high temperature carbonaceous environment, ${ }^{\mathbf{1 1 , 1 2}}$ and $\mathrm{MnCr}_{2} \mathrm{O}_{4}$ spinel is much more stable than $\mathrm{Cr}_{2} \mathrm{O}_{3}{ }^{11}$ The chemical state of elements also had remarkable influence on the stability of oxides under high temperature carbonaceous environment. ${ }^{13}$

Even though oxidation behaviors of $\mathrm{Fe}-\mathrm{Cr}-\mathrm{Ni}$ alloys at different temperatures under low oxygen partial pressure have been investigated, most of them focused on the composition, morphology and anti-coking effect of oxide scales. The oxidation process of alloys under low oxygen partial pressure and the corresponding change of the oxides composition were seldom studied. Moreover, few attentions were paid to investigate the chemical state of elements on the oxide scales. These meaningful studies may provide guidance for people to optimize oxidation parameters. In the present work, oxidation experiments of HP40 alloys were carried out for different times at $1050{ }^{\circ} \mathrm{C}$ under $\mathrm{H}_{2}-$ $\mathrm{H}_{2} \mathrm{O}$ environment. The corresponding changes of distribution and chemical state of elements in oxide scales were also characterized.

\section{Experimental}

Alloy samples in a size of $10 \mathrm{~mm} \times 10 \mathrm{~mm} \times 3 \mathrm{~mm}$ were cut from a HP40 alloy tube by wire cutting, and the chemical 
composition and microstructure of as received alloy are shown in Table 1 and Fig. 1, respectively. Before oxidation, the samples were ground with 200, 400, and 800 grits SiC abrasive papers successively and further cleaned with acetone in an ultrasonic bath. Fig. 2 shows the schematic diagram of oxidation device, and the oxidation environment $\left(\mathrm{H}_{2}-\mathrm{H}_{2} \mathrm{O}\right.$ gas mixture) was generated via bubbling $\mathrm{H}_{2}$ through deionized water at $20{ }^{\circ} \mathrm{C}$. The calculated oxygen partial pressure of this $\mathrm{H}_{2}-\mathrm{H}_{2} \mathrm{O}$ gas mixture at $1050{ }^{\circ} \mathrm{C}$ is about $8.9 \times 10^{-18}$ atm. ${ }^{11}$ Oxidation of samples was performed in the center of a quartz reaction chamber. The reaction chamber was firstly purified by nitrogen purging, and then gas mixture of $\mathrm{H}_{2}-\mathrm{H}_{2} \mathrm{O}$ was introduced into reaction chamber to carry out oxidation experiments. The experiments followed these conditions: flow rate of gas mixture was $100 \mathrm{ml} \mathrm{min} \mathrm{m}^{-1}$, isothermal oxidation temperature was $1050{ }^{\circ} \mathrm{C}$, oxidation time varied from $0.2 \mathrm{~h}$ to $20 \mathrm{~h}$, and both heating and cooling rate were $5{ }^{\circ} \mathrm{C} \mathrm{min}^{-1}$.

After cooling, the characters of oxide scales formed after different oxidation time were detailedly studied. The morphology and elemental distribution of the scales were examined by scanning electron microscope (SEM), energy

Table 1 The main composition of the HP40 alloy (in wt\%)

\begin{tabular}{lllllllll}
\hline $\mathrm{Ni}$ & $\mathrm{Cr}$ & $\mathrm{Mn}$ & $\mathrm{Si}$ & $\mathrm{C}$ & $\mathrm{Nb}$ & $\mathrm{S}$ & $\mathrm{P}$ & $\mathrm{Fe}$ \\
\hline 34.82 & 24.98 & 1.11 & 1.56 & 0.471 & 0.955 & 0.010 & 0.022 & 35.67
\end{tabular}

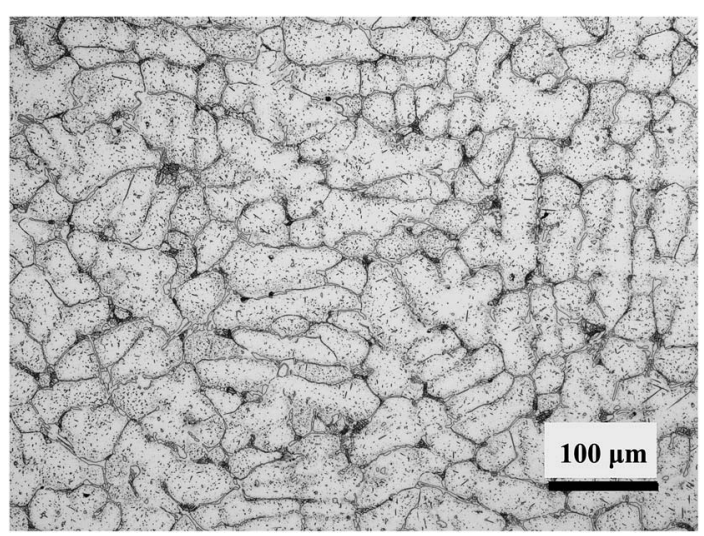

Fig. 1 Microstructure of as received alloy sample.

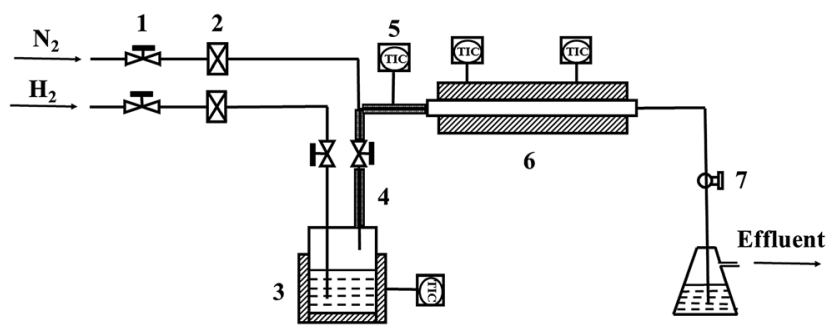

Fig. 2 Schematic diagram of oxidation device: (1) needle valve; (2) gas flowmeter; (3) heating jacket; (4) heating band; (5) temperature controller; (6) reaction chamber; (7) ball valve. dispersive spectrometer (EDS), glow discharge optical emission spectrometry (GD-OES), respectively. The phase composition of the scales was detected by X-ray diffraction (XRD) and Raman spectra. The measurements of Raman spectra utilized $514.5 \mathrm{~nm}$ line of an Ar ion laser at room temperature and recorded in the range of $120-1000 \mathrm{~cm}^{-1}$. And the chemical state of elements on the oxide scales was characterized by X-ray photoelectron spectroscopy (XPS).

\section{Results and discussion}

\subsection{Morphology and elemental distribution of oxide scales}

Fig. 3(a) shows the morphology and elemental distribution of the oxide scales formed under $\mathrm{H}_{2}-\mathrm{H}_{2} \mathrm{O}$ environment after $0.2 \mathrm{~h}$ isothermal oxidation. A small amount of crystals appears at grain boundaries on the alloy surface, and which displays granular structures with some blade-like structures scattered over. According to EDS maps, the crystals at grain boundaries obviously consist of $\mathrm{Mn}, \mathrm{Cr}$ and $\mathrm{O}$ elements, while the concentrations of $\mathrm{Cr}, \mathrm{Mn}$ and $\mathrm{O}$ elements in the regions between the boundaries are much lower. According to previous reports, ${ }^{3,10,11}$ oxidation of $\mathrm{Fe}$ and $\mathrm{Ni}$ elements is inhibited under proper low oxygen partial pressure $\left(\mathrm{H}_{2}-\mathrm{H}_{2} \mathrm{O}\right.$ environment in this work) due to their lower affinities. During oxidation process, $\mathrm{Cr}$ is initially oxidized to form chromia on alloy surface since its higher thermodynamic activity, then $\mathrm{Cr}$ and $\mathrm{Mn}$ elements diffuse outward across chromia scale and form oxides continuously. The lattice-diffusion rate of $\mathrm{Mn}$ element in chromia is two orders of magnitude higher than that of $\mathrm{Cr},{ }^{\mathbf{1 0 , 1 1}}$ therefore the formed oxides contains remarkable Mn-oxides although the bulk content of $\mathrm{Mn}$ is only about $1 \%$ in the base alloy. After $0.2 \mathrm{~h}$ oxidation, a small amount of $\mathrm{Mn}-\mathrm{Cr}$ composite oxides preferentially form along the grain boundaries, while very thin chromia scales exist in spare regions. It has been reported that oxide-forming elements prefer to diffuse outward across grain boundaries rather than across crystal lattice under low oxygen partial pressure. ${ }^{\mathbf{1 4 - 1 6}}$ Therefore, chromia initially formed at grain boundaries is much more than that formed between grain boundaries. Subsequently, Mn element rapidly diffuses outward across chromia to form Mn oxide due to the much higher diffusion rate of Mn. Finally, the formed Mn oxide would react with $\mathrm{Cr}_{2} \mathrm{O}_{3}$ to form $\mathrm{Mn}-\mathrm{Cr}$ composite oxides. Mn$\mathrm{Cr}$ composite oxides preferentially form along the grain boundaries due to the enrichment of chromia at grain boundaries. The appearance of blade-like structures can be explained by the following process: the blade-like structures initially formed at dislocations of the oxides, and then cations quickly diffuse into the blades due to the presence of hollow cores, finally the blade-like structures grow over the oxides. ${ }^{3,17,18}$ When the oxidation time is prolonged to $2 \mathrm{~h}$, the oxide scales along the grain boundaries are obviously thicker and wider than that oxidized for $0.2 \mathrm{~h}$, and more blade-like structures are present on oxide scales, which are shown in Fig. 3(b). And EDS maps also reveal that more oxides forms both at and between grain boundaries. However, EDS maps also reveal that oxides at and between grain boundaries mainly consist of $\mathrm{Mn}-\mathrm{Cr}$ composite oxides and Cr-oxides, respectively. Besides, considerable 

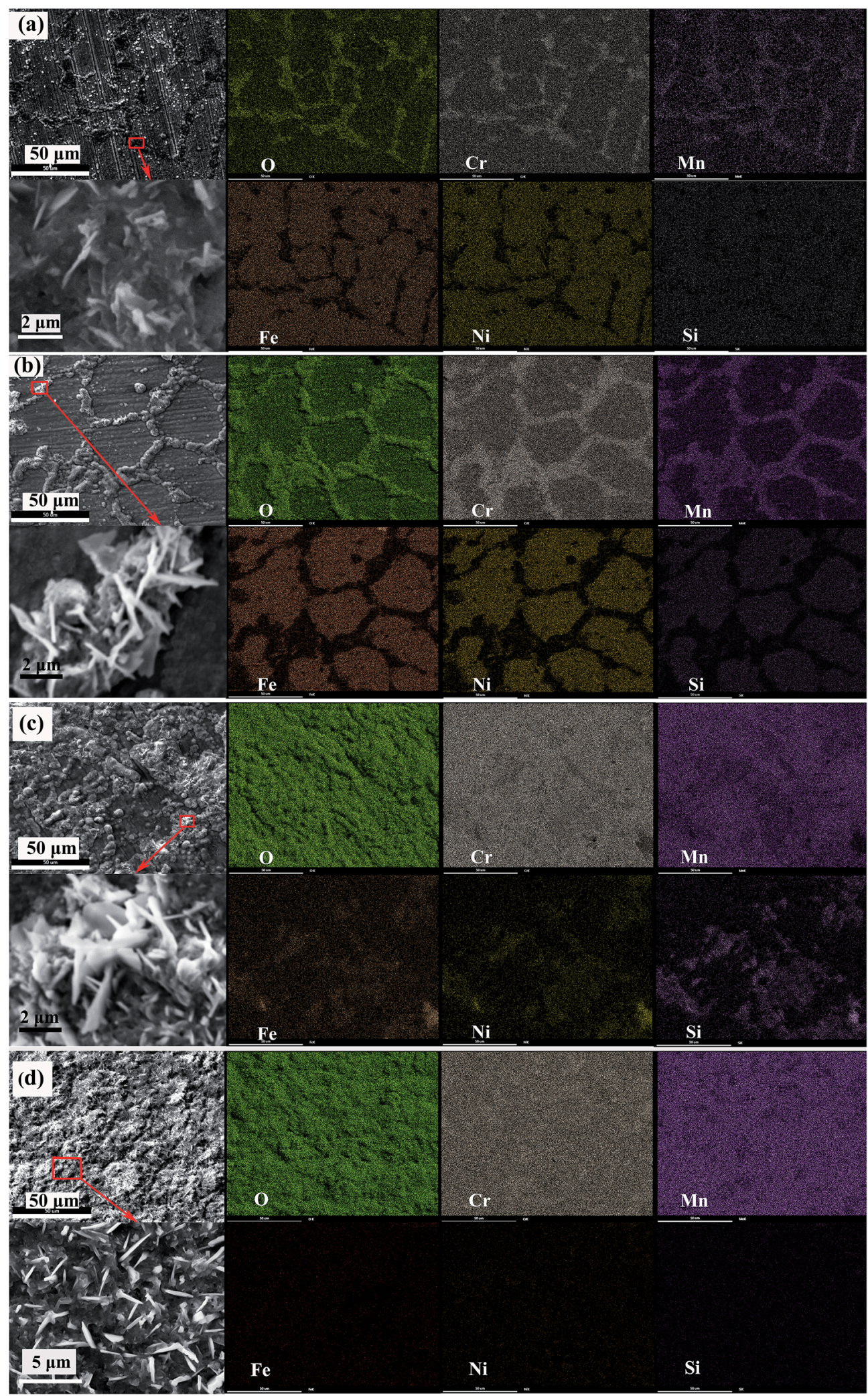

Fig. 3 Morphology and elemental distribution of oxide scales formed under $\mathrm{H}_{2}-\mathrm{H}_{2} \mathrm{O}$ environment after various isothermal oxidation times: (a) 0.2 h; (b) 2 h; (c) 10 h; (d) 20 h.

amount of Si element between grain boundaries is detected by EDS, which can be attributed to the accumulation of Si element under the chromia scale and the penetration of X-ray through the thin chromia scale. ${ }^{10,11}$ After $10 \mathrm{~h}$ oxidation, most of alloy surface is covered by thick $\mathrm{Mn}-\mathrm{Cr}$ oxide scales with blade-like structures scattered over. However, partial regions of alloy 
surface are still covered by thinner scales containing a much lower concentration of Mn element, and the small thickness of scales leads to the presence of $\mathrm{Fe}, \mathrm{Ni}$ and Si elements in EDS maps. When thick scales form at grain boundaries, the outward growth rate is slowed, and the oxide scales grow along the alloy surface, resulting in the gradual coverage of the scales on alloy surface. Fig. 3(d) shows the morphology and elemental distribution of the oxide scales formed under $\mathrm{H}_{2}-\mathrm{H}_{2} \mathrm{O}$ environment after $20 \mathrm{~h}$ isothermal oxidation. The morphology analysis exhibits that, alloy surface is fully covered by granular crystals as well as scattered blade-like structures. Furthermore, Fe, Ni and Si elements are not detected by EDS analysis, indicating considerable thickness of oxide scales. The morphology and a uniform distribution of $\mathrm{Mn}, \mathrm{Cr}$ and $\mathrm{O}$ elements demonstrate that uniform scales composed of $\mathrm{Mn}-\mathrm{Cr}$ composite oxides formed on alloy surface after $20 \mathrm{~h}$ oxidation.

\subsection{Cross-section morphology and elemental distribution of oxide scales}

Fig. 4 shows the morphology and elemental distribution of the cross-section of oxide scales formed under $\mathrm{H}_{2}-\mathrm{H}_{2} \mathrm{O}$ environment after various isothermal oxidation times. Dense scales without any cracks and voids are observed on the surfaces, and the thickness increased from about $200 \mathrm{~nm}$ to $2 \mu \mathrm{m}$ with increasing oxidation time. The results of EDS line scan analyses show that $\mathrm{Mn}-\mathrm{Cr}-\mathrm{O}$ and chromia duplex oxide scales are displayed on alloy surfaces after various oxidation times, and Si-rich oxides can be found at the interfaces of oxide scale and base alloy. After $0.2 \mathrm{~h}$ oxidation, oxide scale with a thickness of about $200 \mathrm{~nm}$ formed on the surface, and the oxide scale mainly composed of chromia, the concentration of $\mathrm{Mn}$ in the scale rapidly decreased along the thickness. After $2 \mathrm{~h}, 10 \mathrm{~h}$ and $20 \mathrm{~h}$, the thicknesses of oxide scales increase to $500 \mathrm{~nm}, 1.5 \mu \mathrm{m}$ and $2 \mu \mathrm{m}$, respectively. Moreover, the thickness of $\mathrm{Mn}-\mathrm{Cr}-\mathrm{O}$ oxide and the content of Si-rich oxides increase with oxidation time. After $20 \mathrm{~h}$ oxidation, $\mathrm{Mn}-\mathrm{Cr}-\mathrm{O}$ oxide layer with nearly $1 \mu \mathrm{m}$ thickness formed on alloy surface, and an obvious Si-rich oxide transition layer formed at the interface of oxide scale and base alloy. According to previous reports, ${ }^{19-21} \mathrm{Si}-$ rich oxide could develop at scale/substrate interface when $\mathrm{H}$ series heat-resistance alloy was oxidized at atmospheric environment or $\mathrm{CO}-\mathrm{CO}_{2}$ gas mixtures, and the formed Si-rich oxide layer was discrete and scattered near the interface. However, Si-rich oxide layer distributed uniformly along the scale/substrate interface when the alloy was oxidized under $\mathrm{H}_{2}-\mathrm{H}_{2} \mathrm{O}$ environment.

It has been reported that hydrogen can dissolve into chromia scales formed in water-containing environment. ${ }^{22-25}$ In order to see hydrogen distribution in oxide scales, GD-OES measurements were carried out for alloy samples oxidized for 0.2-20 h. GD-OES depth profiles of oxide scales formed under $\mathrm{H}_{2}-\mathrm{H}_{2} \mathrm{O}$ environment after various isothermal oxidation times are displayed in Fig. 5. According to the profiles, the elemental distributions of $\mathrm{Fe}, \mathrm{Ni}, \mathrm{Cr}, \mathrm{Mn}, \mathrm{O}$ and Si elements are in accordance with EDS analyses above. GD-OES analyses indicate small amount of hydrogen existed throughout oxide scales, and enriched at the surfaces and oxide/substrate interfaces. And the content of hydrogen at oxide/substrate interface decreased with oxidation time. The existence of hydrogen at the surfaces probably caused by water adsorption and the reaction of water and oxides. $^{23,26}$ It was reported that the oxide structure formed on alloy surface was a poor barrier to $\mathrm{H}$-species penetration, and $\mathrm{H}$ species probably originated from $\mathrm{H}_{2} \mathrm{O}$ for chromia scale growing at low oxygen partial pressure environment created by $\mathrm{H}_{2}-$ $\mathrm{H}_{2} \mathrm{O}^{24,25}$ When Cr cations cross metal/oxide interface to facilitate oxide scale growth, H-species would support Rahmel-Tobolski mechanism in pores at metal/oxide interface and subsequently close pores at the interface. ${ }^{23-25}$ Similar enrichments of hydrogen at metal/oxide interface of alloy were also found in other researches involving $\mathrm{H}_{2} \mathrm{O}$-containing atmosphere. . $^{2,24}$

\subsection{Phase composition of oxide scales}

Fig. 6 shows the XRD patterns of alloy samples oxidized at $1050{ }^{\circ} \mathrm{C}$ under $\mathrm{H}_{2}-\mathrm{H}_{2} \mathrm{O}$ environment after various isothermal
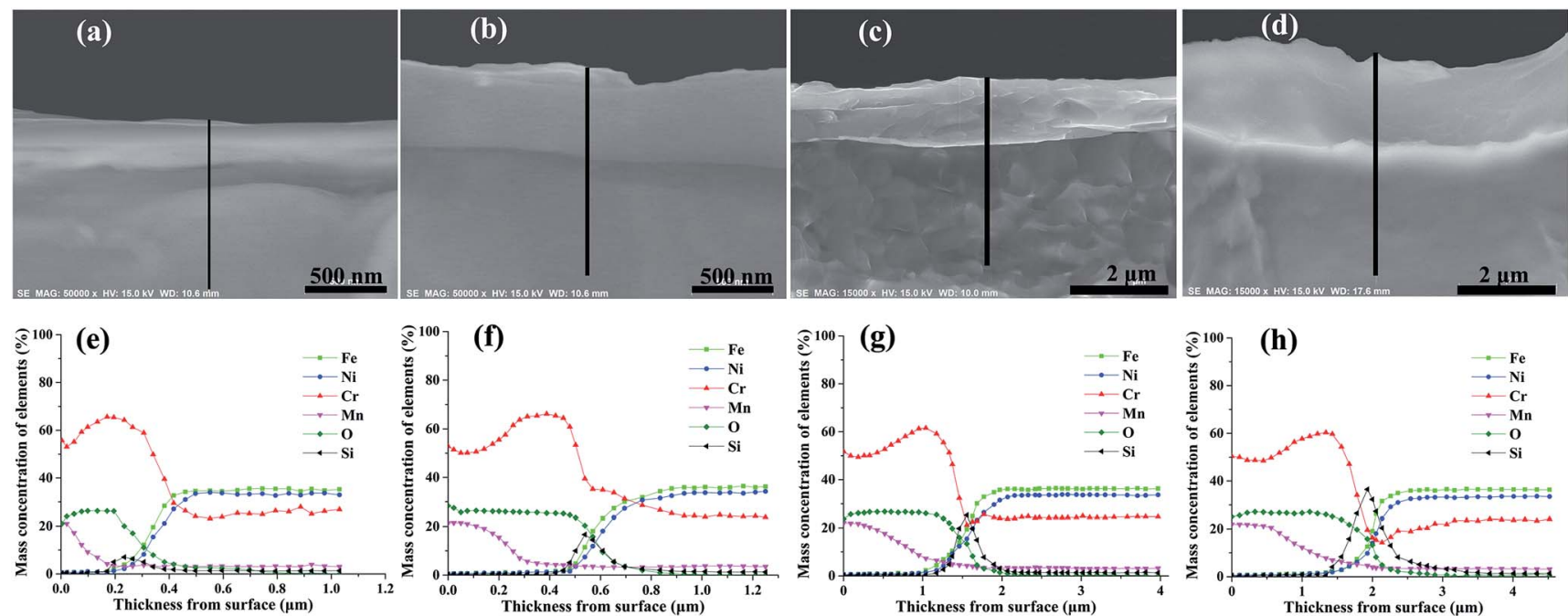

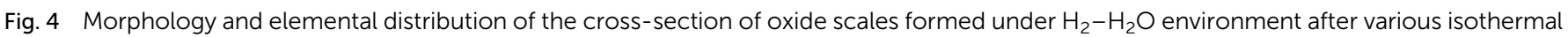
oxidation times: (a, e) 0.2 h; (b, f) 2 h; (c, g) 10 h; (d, h) 20 h. 

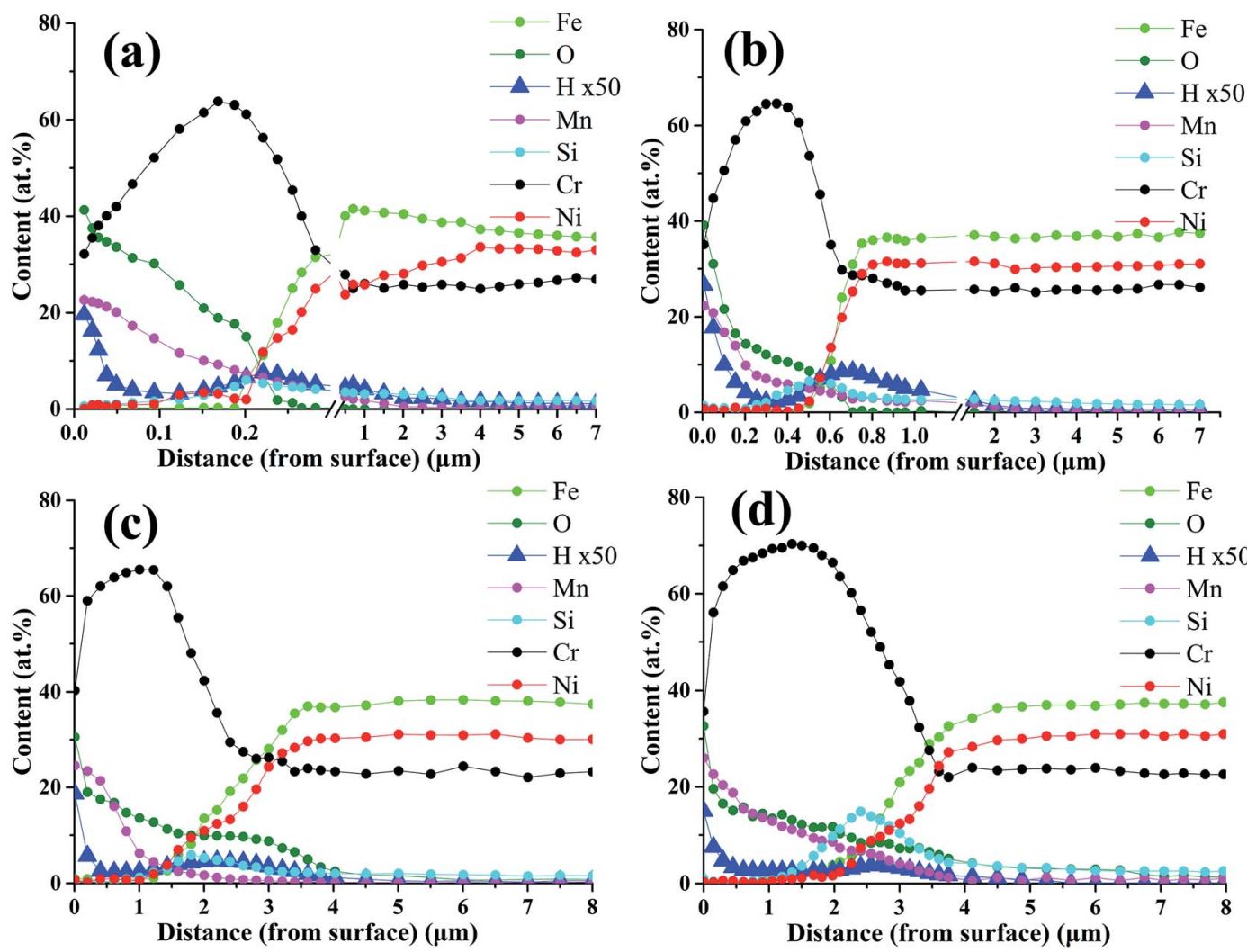

Fig. 5 GD-OES profile of oxide scales formed under $\mathrm{H}_{2}-\mathrm{H}_{2} \mathrm{O}$ environment after various isothermal oxidation times: (a) $0.2 \mathrm{~h}$; (b) $2 \mathrm{~h}$; (c) $10 \mathrm{~h}$; (d) $20 \mathrm{~h}$.

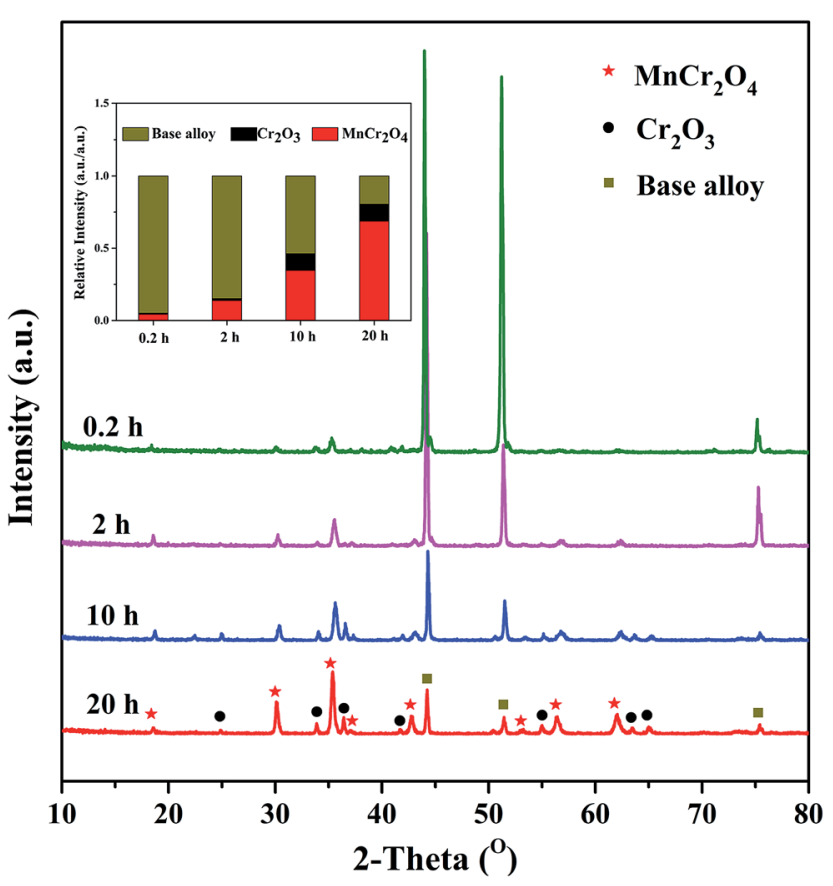

Fig. 6 XRD patterns of alloy samples oxidized at $1050{ }^{\circ} \mathrm{C}$ under $\mathrm{H}_{2}-$ $\mathrm{H}_{2} \mathrm{O}$ environment after various isothermal oxidation times.

oxidation times. It can be observed that the oxide scales formed after various oxidation times are mainly composed of $\mathrm{MnCr}_{2} \mathrm{O}_{4}$ spinel phase and $\mathrm{Cr}_{2} \mathrm{O}_{3}$ phase, demonstrating selective oxidation of $\mathrm{Cr}$ and $\mathrm{Mn}$ elements are realized under experimental environment. Although peaks in all patterns can be assigned to base alloy, $\mathrm{MnCr}_{2} \mathrm{O}_{4}$ spinel and $\mathrm{Cr}_{2} \mathrm{O}_{3}$, significant difference appears in terms of relative intensities. The insert figure in Fig. 6 exhibits the relative peak intensities of base alloy, $\mathrm{MnCr}_{2} \mathrm{O}_{4}$ spinel and $\mathrm{Cr}_{2} \mathrm{O}_{3}$. The results show that the relative intensity of oxides $\left(\mathrm{MnCr}_{2} \mathrm{O}_{4}\right.$ spinel and $\left.\mathrm{Cr}_{2} \mathrm{O}_{3}\right)$ significantly increases with oxidation time, indicating remarkable increase in thickness of oxide scales. After $20 \mathrm{~h}$ oxidation at $1050{ }^{\circ} \mathrm{C}$ under $\mathrm{H}_{2}-\mathrm{H}_{2} \mathrm{O}$ environment, alloy surface is fully covered by dense and uniform oxide scale. It was reported that $\mathrm{MnCr}_{2} \mathrm{O}_{4}$ spinel was much more stable than $\mathrm{Cr}_{2} \mathrm{O}_{3}$ in high temperature thermal cracking environment. ${ }^{11-13}$ Therefore, alloy oxidized under this condition is considered to have favorable performance in thermal cracking environment.

Raman spectrum is sensitive to crystal structures and has small penetration depth, therefore it can well characterize the phase structure on the surface of oxide scales. ${ }^{27-32}$ Fig. 7 shows Raman spectra of the oxide scales formed under $\mathrm{H}_{2}-\mathrm{H}_{2} \mathrm{O}$ environment after various oxidation times. Three peaks assigned to $\mathrm{Cr}_{2} \mathrm{O}_{3}$ (centered at $530 \mathrm{~cm}^{-1}, 555 \mathrm{~cm}^{-1}$ and $625 \mathrm{~cm}^{-1}$ ), ${ }^{28-30}$ three peaks assigned to $\mathrm{MnCr}_{2} \mathrm{O}_{4}$ (centered at $511 \mathrm{~cm}^{-1}, 600 \mathrm{~cm}^{-1}$ and $685 \mathrm{~cm}^{-1}$ ) ${ }^{10,31}$ and two peaks assigned to Si-oxides (centered at $296 \mathrm{~cm}^{-1}$ and $\left.350 \mathrm{~cm}^{-1}\right)^{32}$ can be found in Raman spectra. Raman spectra of the oxide scales exhibit remarkable difference, especially in the relative amount of phases. The results indicate that the relative amount of $\mathrm{Cr}_{2} \mathrm{O}_{3}$ is much larger than that of $\mathrm{MnCr}_{2} \mathrm{O}_{4}$ on the surface of oxide scale after $0.2 \mathrm{~h}$ 


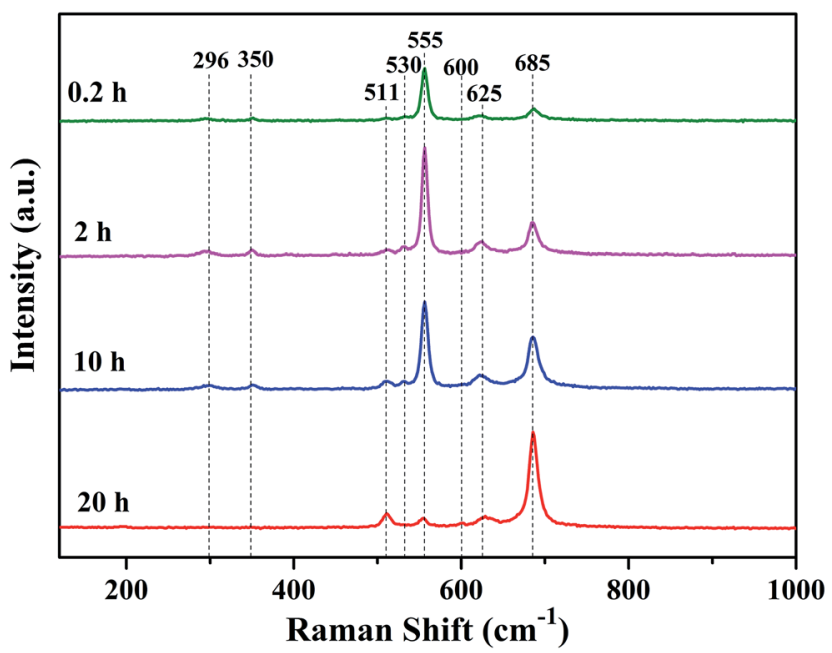

Fig. 7 Raman spectra of oxide scales formed under $\mathrm{H}_{2}-\mathrm{H}_{2} \mathrm{O}$ environment after various oxidation times.

oxidation. With the extension of oxidation time, the relative amount of $\mathrm{Cr}_{2} \mathrm{O}_{3}$ decreases rapidly while the relative amount of $\mathrm{MnCr}_{2} \mathrm{O}_{4}$ quickly increases. After $20 \mathrm{~h}$ oxidation, the surface of oxide scale consists a majority of $\mathrm{MnCr}_{2} \mathrm{O}_{4}$ and just a spot of $\mathrm{Cr}_{2} \mathrm{O}_{3}$. Moreover, Si-oxide phase can only be found in Raman spectra of alloy surfaces oxidized for $0.2 \mathrm{~h}, 2 \mathrm{~h}$ and $10 \mathrm{~h}$, which can be explained by the penetration of laser. It can be noticed that, even though the content of $\mathrm{Cr}_{2} \mathrm{O}_{3}$ in the whole oxide scale is very low, $\mathrm{Cr}_{2} \mathrm{O}_{3}$ appears as the main phase on the surface of oxide scale when oxidation time is $0.2 \mathrm{~h}, 2 \mathrm{~h}$ or $10 \mathrm{~h}$.

\subsection{Chemical state of elements on the oxide scales}

Since the surface of oxide scale directly contacts with thermal cracking gas, surface state of the oxide scale significantly influences its anti-coking and anti-carburizing properties. The chemical state of elements on oxide scales were characterized by XPS spectra, and all spectra were energy calibrated with $\mathrm{C} 1 \mathrm{~s}$ standard energy value of $284.8 \mathrm{eV}$. XPS spectra only show peaks corresponding to O, C, Mn and Cr elements (shown in Fig. $\mathrm{S} 1 \dagger$ ). Among them, peaks assigned to $\mathrm{C}$ originate from adventitious hydrocarbons in the XPS instrument, while peaks assigned to C, $\mathrm{Mn}$ and $\mathrm{Cr}$ elements are from oxide scales. The XPS result for elemental composition is in line with previous EDS, XRD and Raman analyses. Therefore, the chemical states of O, Cr and Mn elements are finely studied by high resolution XPS spectra. Fig. 8 shows XPS spectra and corresponding fitting lines of $\mathrm{O} 1 \mathrm{~s}$ regions for oxide scales after $0.2-20 \mathrm{~h}$ oxidation. In all spectra, two peaks centered at binding energies (BE) $530.2 \mathrm{eV}$ and $531.8 \mathrm{eV}$ were fitted, and the fitting lines showed good agreement with observed spectra. According to numerous reports, the peaks centered at BE $530.2 \mathrm{eV}$ and $531.8 \mathrm{eV}$ are assigned to $\mathrm{O}^{2-}$ ions in metal oxides and hydroxides, ${ }^{33,34}$ respectively, and
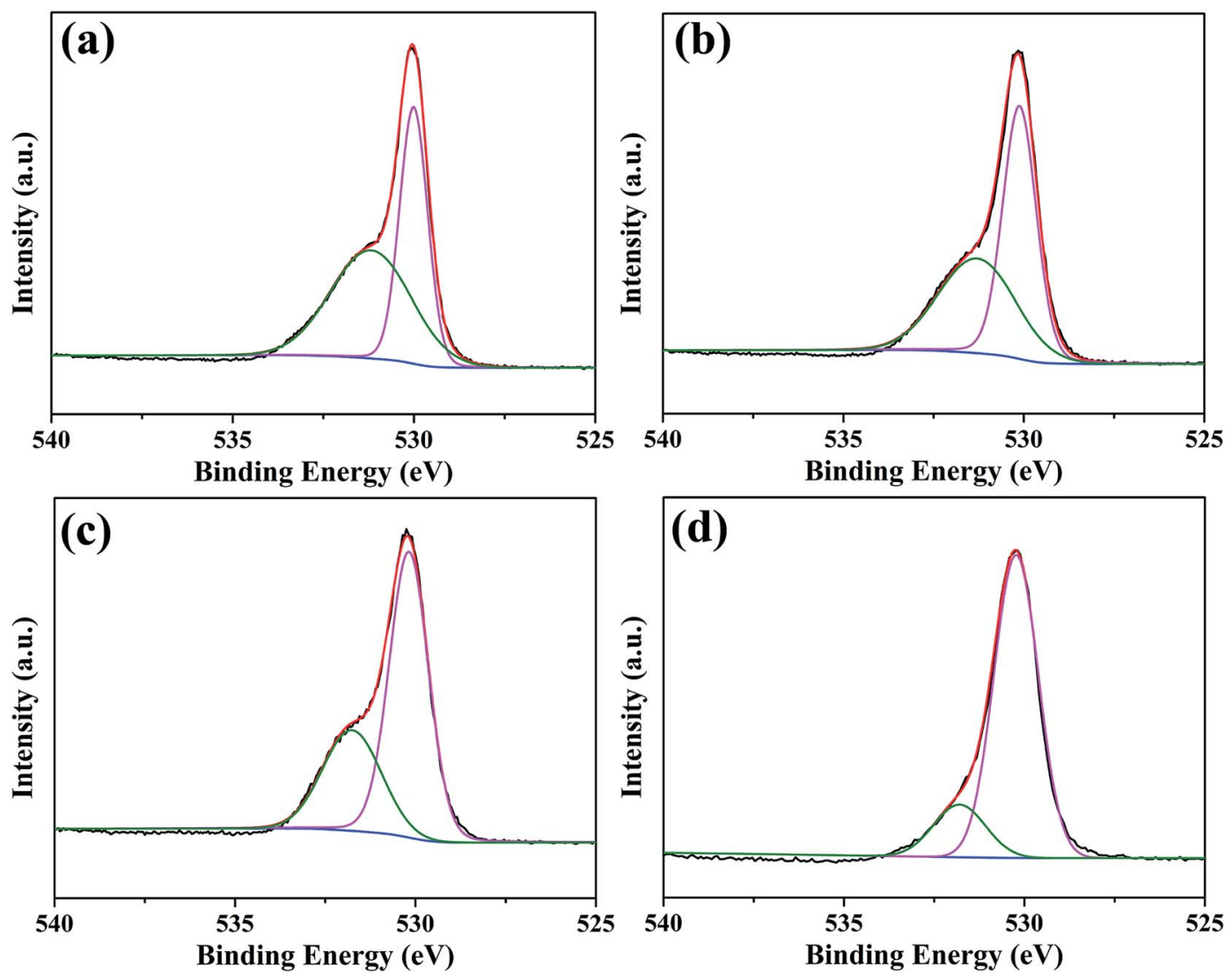

Fig. 8 XPS spectra and corresponding fitting lines of $\mathrm{O}$ 1s regions for oxide scales formed after various oxidation times: (a) $0.2 \mathrm{~h}$; (b) $2 \mathrm{~h}$; (c) $10 \mathrm{~h}$; (d) $20 \mathrm{~h}$. 
the presence of hydroxides can be attributed to the reaction of water vapor in oxidation environment and metal elements. ${ }^{15,26,35}$ It can be found that the relative intensity of peak centered at $\mathrm{BE}$ $531.8 \mathrm{eV}$ decreased rapidly with increasing oxidation time. Relative intensities of these two species on oxide scales are calculated based on peak area, revealing that the content of species containing metal hydroxides decreases from $53.7 \%$ to $16.9 \%$ when oxidation time is extended from $0.2 \mathrm{~h}$ to $20 \mathrm{~h}$ (Fig. S2 $\dagger$ ). With the extension of oxidation time, more $\mathrm{MnCr}_{2} \mathrm{O}_{4}$ spinel form and gradually cover the surface, so that high stability of $\mathrm{MnCr}_{2} \mathrm{O}_{4}$ spinel leads to the reduction of metal hydroxides.

Fig. 9 shows XPS spectra and corresponding fitting lines of Cr $2 \mathrm{p}_{3 / 2}$ and $\operatorname{Cr} 2 \mathrm{p}_{1 / 2}$ regions for oxide scales after $0.2-20 \mathrm{~h}$ oxidation. Cr $2 \mathrm{p}_{3 / 2}$ and $\mathrm{Cr} 2 \mathrm{p}_{1 / 2}$ regions of all spectra display wide and complex shapes, indicating the existence of various peaks. After refined fitting, $\mathrm{Cr} 2 \mathrm{p}_{3 / 2}$ region of each spectrum has been deconvoluted into four peaks centered at $\mathrm{BE} 575.6 \mathrm{eV}$, $576.6 \mathrm{eV}, 577.4 \mathrm{eV}$ and $578.1 \mathrm{eV}$, and $\mathrm{Cr} 2 \mathrm{p}_{1 / 2}$ region of each spectrum has been deconvoluted into two peaks centered at BE $585.3 \mathrm{eV}$ and $586.3 \mathrm{eV}$. The peaks centered at $\mathrm{BE} 575.6 \mathrm{eV}$, $576.6 \mathrm{eV}, 585.3 \mathrm{eV}$ and $586.3 \mathrm{eV}$ are attributed to $\mathrm{Cr}^{3+}$ ions, ${ }^{36-38}$ the peak centered at $\mathrm{BE} 577.4 \mathrm{eV}$ is ascribed to Chromium hydroxide and the peak centered at $\mathrm{BE} 578.1 \mathrm{eV}$ corresponds to $\mathrm{Cr}^{6+}$ ions. ${ }^{38,39}$ Among these species, $\mathrm{Cr}^{3+}$ ions exist in $\mathrm{Cr}$ containing composite oxides $\left(\mathrm{Cr}_{2} \mathrm{O}_{3}\right.$ and $\left.\mathrm{MnCr}_{2} \mathrm{O}_{4}\right), \mathrm{Cr}^{6+}$ and chromium hydroxide probably exists in the intermediate responsible for chromium evaporation. ${ }^{15,35}$ The relative amounts of these species determined by peak intensities show that just a small proportion of chromium hydroxide and $\mathrm{Cr}^{6+}$ ions exists on the surface after $20 \mathrm{~h}$ oxidation (Fig. S3†).

XPS spectra and corresponding fitting lines of $\mathrm{Mn} 2 \mathrm{p}_{3 / 2}$ and Mn 2 $\mathrm{p}_{1 / 2}$ regions for oxide scales after $0.2-20 \mathrm{~h}$ oxidation are displayed in Fig. 10. According to fitting lines, each spectrum displays a peak centered at $\mathrm{BE} 652.3 \mathrm{eV}$ in $\mathrm{Mn} 2 \mathrm{p}_{1 / 2}$ region, two peaks centered at $\mathrm{BE} 640.9 \mathrm{eV}$ and $639.7 \mathrm{eV}$ in $\mathrm{Mn} 2 \mathrm{p}_{3 / 2}$ region and a satellite peak centered at $\mathrm{BE} 646.4 \mathrm{eV}$. In addition, another peak centered at BE $651.2 \mathrm{eV}$ is only present in XPS spectrum for oxide scale formed after $0.2 \mathrm{~h}$ oxidation. It has been reported that, the peaks centered at $\mathrm{BE} 639.7 \mathrm{eV}, 640.9 \mathrm{eV}$, $651.2 \mathrm{eV}$ and $652.3 \mathrm{eV}$ are assigned to $\mathrm{Mn}^{2+}$ ions, and the satellite feature centered at $\mathrm{BE} 646.4 \mathrm{eV}$ is also a typical feature for $\mathrm{Mn}^{2+}$ ions. ${ }^{40-42}$ Binding energy difference $(\Delta \mathrm{BE})$ in $\mathrm{Mn} 3 \mathrm{~s}$ region of XPS spectrum is another important parameter to distinguish chemical state of Mn element, and $\Delta \mathrm{BEs}$ of $6.0 \mathrm{eV}$, $5.3 \mathrm{eV}$ and $4.7 \mathrm{eV}$ correspond to $\mathrm{Mn}^{2+}, \mathrm{Mn}^{3+}$, and $\mathrm{Mn}^{4+}$ ions, respectively. ${ }^{43} \Delta$ BEs of $\mathrm{Mn} 3 \mathrm{~s}$ regions for all the oxide scales are $6.0 \mathrm{eV}$ (Fig. $\mathrm{S} 4 \dagger$ ), confirming that Mn species on all oxide scales exist in the form of $\mathrm{Mn}^{2+}$ ions. Moreover, it was reported that the peak position of $\mathrm{Mn}^{2+}$ ions existed in oxides is significantly influenced by oxide structures, the peak positions of $\mathrm{Mn}^{2+}$ ions in octahedral site and tetragonal site appear at BE $640.9 \mathrm{eV}$ and
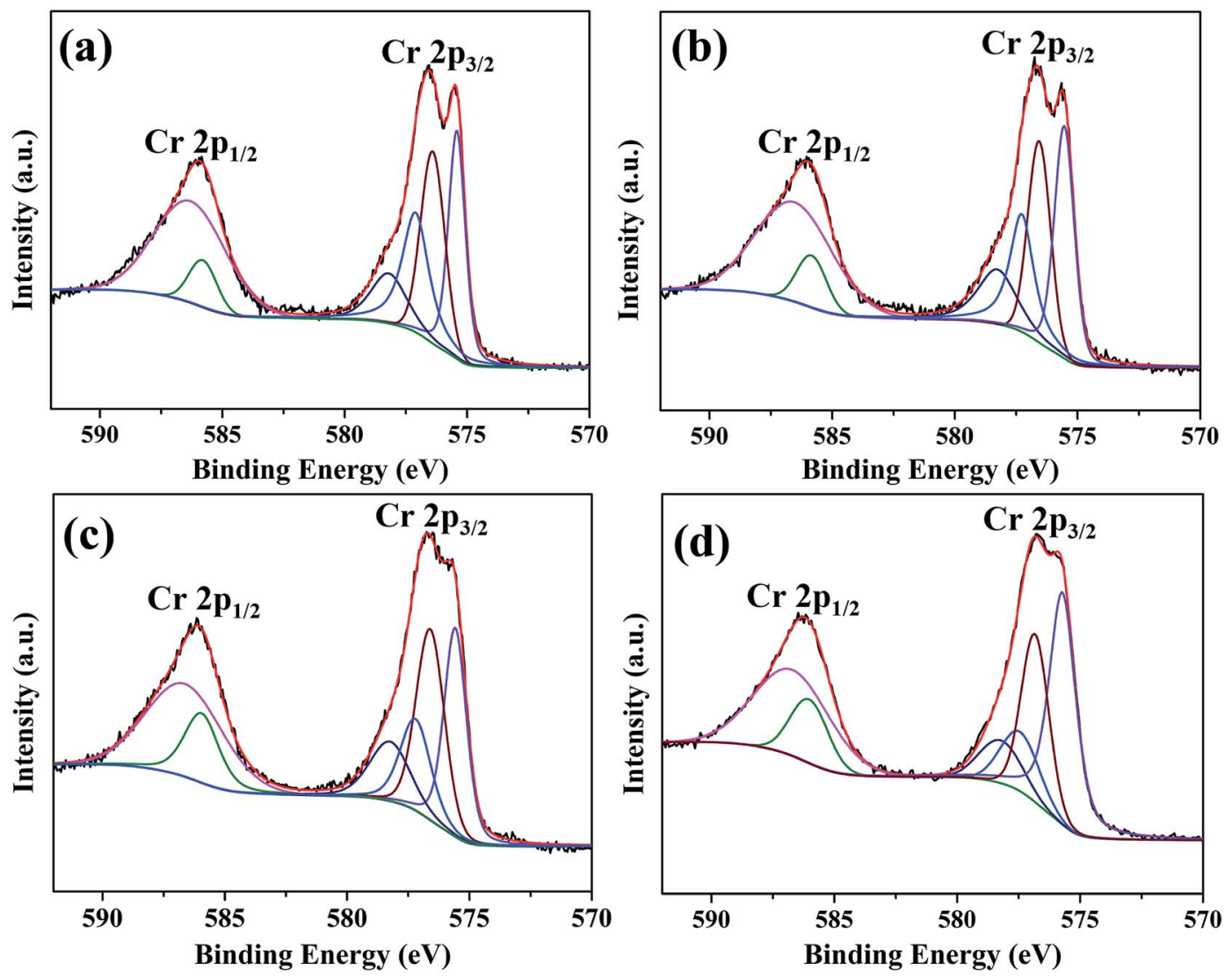

Fig. 9 XPS spectra and corresponding fitting lines of $\mathrm{Cr} 2 \mathrm{p}_{3 / 2}$ and $\mathrm{Cr} 2 \mathrm{p}_{1 / 2}$ regions for oxide scales formed after various oxidation times: (a) $0.2 \mathrm{~h}$; (b) $2 \mathrm{~h}$; (c) $10 \mathrm{~h}$; (d) $20 \mathrm{~h}$. 

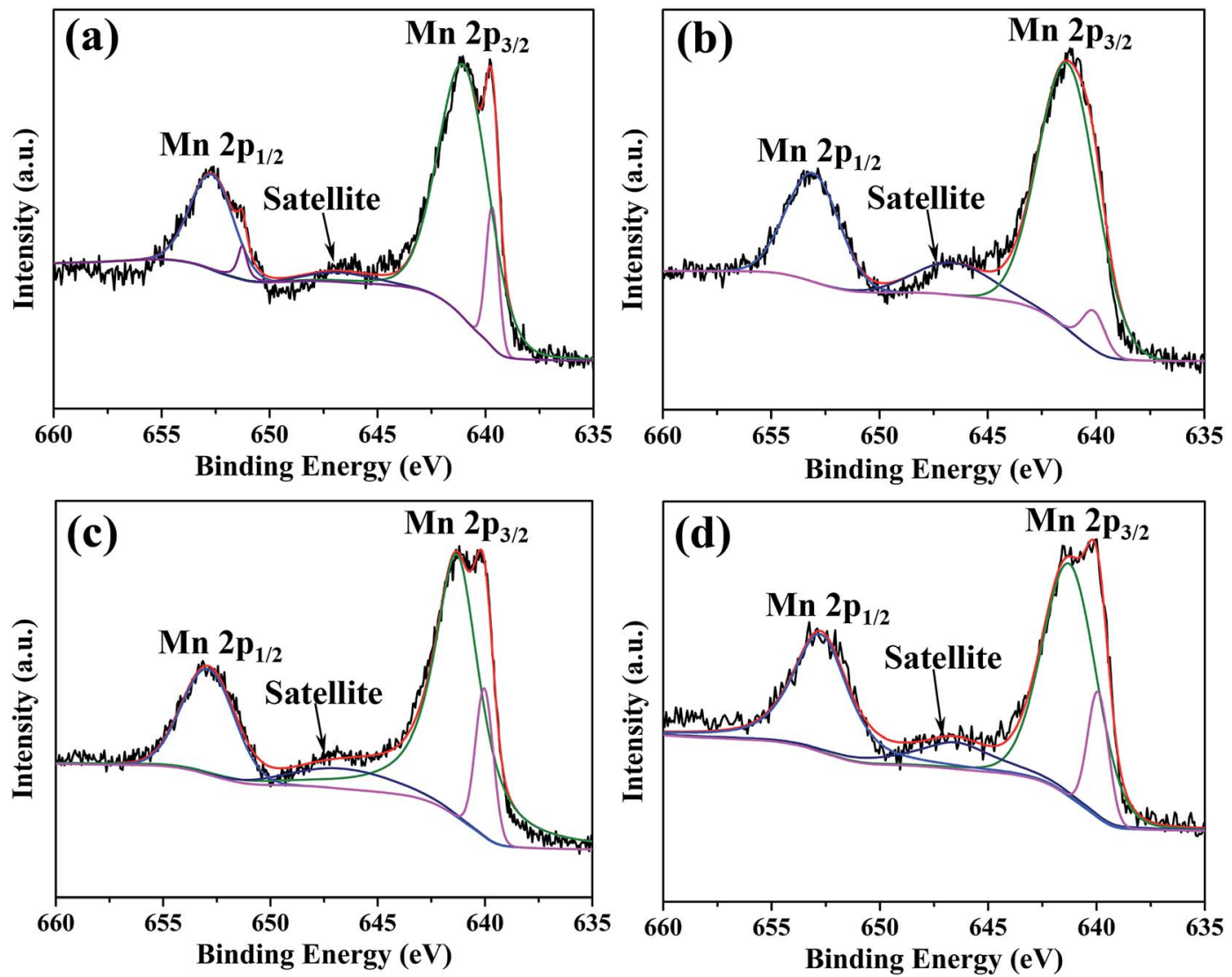

Fig. 10 XPS spectra and corresponding fitting lines of $M n 2 p_{3 / 2}$ and $M n 2 p_{1 / 2}$ regions for oxide scales formed after various oxidation times: (a) $0.2 \mathrm{~h}$; (b) $2 \mathrm{~h}$; (c) $10 \mathrm{~h}$; (d) $20 \mathrm{~h}$.

$639.7 \mathrm{eV}$, respectively. ${ }^{41}$ In each spectrum, the intensity of peak centered at $\mathrm{BE} 640.9 \mathrm{eV}$ is much higher than that of peak centered at $\mathrm{BE} 639.7 \mathrm{eV}$, indicating octahedral structure is the main structure for all oxides.

\section{Conclusion}

In the present work, high temperature selective oxidation of HP40 alloy were investigated in terms of morphology, elemental distribution, phase composition and chemical state of elements on the surface.

Selective oxidation of $\mathrm{Mn}$ and $\mathrm{Cr}$ elements is realized under low oxygen partial pressure (created by $\mathrm{H}_{2}-\mathrm{H}_{2} \mathrm{O}$ environment), $\mathrm{Mn}-\mathrm{Cr}$ oxide scales initially grow across the grain boundaries rather than across the grain lattice, then gradually cover the whole surface. The oxide scales exhibit small granular crystals with blade-like structures scattered over throughout the oxidation process.

The oxide scales consist $\mathrm{MnCr}_{2} \mathrm{O}_{4}$ and chromia duplex structure, and enrichment of hydrogen is found at the surfaces and oxide/substrate interfaces of the oxidized alloys. With oxidation time, the main phase composition of surface layer of oxide scale significantly changes from $\mathrm{Cr}_{2} \mathrm{O}_{3}$ to $\mathrm{MnCr}_{2} \mathrm{O}_{4}$ spinel.

$\mathrm{O}$ element on the surface exists in both metal oxides and hydroxyl groups, and the species containing metal hydroxides significantly reduce with oxidation time. Throughout the oxidation process, Cr element can be assigned to $\mathrm{Cr}^{6+}$ ions, $\mathrm{Cr}^{3+}$ ions in Cr-containing composite oxides (mainly $\mathrm{MnCr}_{2} \mathrm{O}_{4}$ ) and chromium hydroxide, while Mn element is only attributed to $\mathrm{Mn}^{2+}$ ions.

\section{Acknowledgements}

This work is gratefully supported by Research Fund for the Doctoral Program of Higher Education of China (20110074110009) and Sinopec Corp., China.

\section{References}

1 J. Wang, M.-F. Reyniers, K. M. Van Geem and G. B. Marin, Ind. Eng. Chem. Res., 2008, 47, 1468-1482.

2 J. Wang, M.-F. Reyniers and G. B. Marin, Ind. Eng. Chem. Res., 2007, 46, 4134-4148.

3 M. Shao, L. Cui, Y. Zheng, Y. Wang and L. Xing, Mater. Corros., 2013, 64, 777-782.

4 J. Zhou, H. Xu, X. Luan and X. Ling, Fuel Process. Technol., 2012, 104, 198-203.

5 L. F. Albright and J. C. Marek, Ind. Eng. Chem. Res., 1988, 27, 755-759.

6 S. Tang, S. Gao, S. Hu, J. Wang, Q. Zhu, Y. Chen and X. Li, Ind. Eng. Chem. Res., 2014, 53, 5432-5442.

7 C. Li and Y. Yang, Surf. Coat. Technol., 2004, 185, 68-73. 
8 S. Tang, J. Wang, Q. Zhu, Y. Chen and X. Li, ACS Appl. Mater. Interfaces, 2014, 6, 17157-17165.

9 Z. Zhang and L. F. Albright, Ind. Eng. Chem. Res., 2010, 49, 1991-1994.

10 B. Bao, J. Liu, H. Xu, B. Liu and W. Zhang, $R S C A d v .$, 2016, 6, 68934-68941.

11 H. Li and W. Chen, Corros. Sci., 2010, 52, 2481-2488.

12 H. Li, Y. Zheng, L. W. Benum, M. Oballa and W. Chen, Corros. Sci., 2009, 51, 2336-2341.

13 H. Li and W. Chen, Corros. Sci., 2011, 53, 2097-2105.

14 T. Horita, Y. Xiong, K. Yamaji, N. Sakai and H. Yokokawa, Fuel Cells, 2002, 2, 189-194.

15 H. Asteman, J.-E. Svensson, M. Norell and L.-G. Johansson, Oxid. Met., 2000, 54, 11-26.

16 J. Zurek, G. H. Meier, E. Essuman, M. Hänsel, L. Singheiser and W. J. Quadakkers, J. Alloys Compd., 2000, 467, 450-458.

17 R. L. Tallman and E. A. Gulbransen, J. Electrochem. Soc., 1967, 114, 1227-1230.

18 E. A. Polman, T. Fransen and P. J. Gellings, Oxid. Met., 1989, 32, 433-447.

19 J. Yan, Y. Gao, L. Liang, Z. Ye, Y. Li, W. Chen and J. Zhang, Corros. Sci., 2011, 53, 329-337.

20 J. Yan, Y. Gao, Y. Shen, F. Yang, D. Yi, Z. Ye, L. Liang and Y. Du, Corros. Sci., 2011, 53, 3588-3595.

21 N. Xu, D. Monceau, D. Young and J. Furtado, Corros. Sci., 2008, 50, 2398-2406.

22 G. Hultquist, B. Tveten and E. Hörnlund, Oxid. Met., 2000, 54, 1-10.

23 A. Yamauchi, Y. Yamauchi, Y. Hirohata, T. Hino and K. Kurokawa, Mater. Sci. Forum, 2006, 522, 163-170.

24 M. Hänsel, L. Garcia-Fresnillo, S. L. Tobing and V. Shemet, Mater. High Temp., 2012, 29, 187-192.

25 M. P. Brady, M. Fayek, J. R. Keiser, H. M. Meyer III, K. L. More, L. M. Anovitz, D. J. Wesolowski and D. R. Cole, Corros. Sci., 2011, 53, 1633-1638.

26 C. Gindort, L. Singheiser and K. Hilpert, J. Phys. Chem. Solids, 2005, 66, 384-387.
27 Z. Zhai, H. Shen, J. Chen, J. Li and S. Zhang, RSC Adv., 2016, 6, 42353-42360.

28 S. M. Abbas, N. Ahmad, A.-U. Rehman, U. A. Rana, S. U.-D. Khan, S. Hussain and K.-W. Nam, Electrochim. Acta, 2016, 212, 260-269.

29 B. D. Hosterman, Physics, Ph.D. thesis, University of Nevada, 2011.

30 D. Bersani, P. P. Lottici, G. Antonioli, E. Campani, A. Casoli and C. Violante, J. Raman Spectrosc., 2004, 35, 694-703.

31 Y. Chen, Z. Liu, S. Ringer, Z. Tong, X. Cui and Y. Chen, Cryst. Growth Des., 2007, 7, 2279-2281.

32 J. Zhou, H. Xu, J. Liu, X. Qi, L. Zhang and Z. Jiang, Mater. Lett., 2007, 61, 5087-5090.

33 S. Ningshen, U. Kamachi, V. K. Mittal and H. S. Khatak, Corros. Sci., 2007, 49, 481-496.

34 M. E. Simonsen, H. Jensen, Z. Li and E. G. Søgaard, J. Photochem. Photobiol., A, 2008, 200, 192-200.

35 R. F. A. Pettersson, J. Enecker and L. Liu, Mater. High Temp., 2005, 22, 269-281.

36 W. E. Mahmoud, Mater. Lett., 2016, 177, 42-45.

37 D. Peng, X. Bai, R. Yu, X. Chen, Q. Zhou, X. Liu and P. Deng, Electrochim. Acta, 2004, 49, 1403-1408.

38 V. Shankar Rao and L. K. Singhal, ISIJ Int., 2009, 49, 19021906.

39 L. Li, Z. Wang, Q. Liu, C. Ye, Z. Chen and L. Gong, Electrochim. Acta, 2012, 77, 89-96.

40 J. Hou, H. Zhao, F. Huang, Q. Jing, H. Gao, Q. Wu, S. Peng and G. Cao, J. Power Sources, 2016, 325, 438-445.

41 R. Wang, C. Yang, Y. Shi, Y. Sun, G. Li, T. Jin, G. Qin, F. Liao and J. Lin, Acta Phys.-Chim. Sin., 2012, 28, 1021-1029.

42 T. Pandiarajan, L. John Berchmans and S. Ravichandran, RSC Adv., 2015, 5, 34100-34108.

43 D. Alburquenque, L. Troncoso, J. C. Denardin, A. Butera, K. D. Padmasree, J. Ortiz, F. Herrera, J. F. Marco and J. L. Gautier, J. Alloys Compd., 2016, 672, 307-316. 